\title{
Falls Associated with Muscle Strength in Patients with Knee Osteoarthritis and Self-reported Knee Instability
}

\author{
Arjan H. de Zwart, Martin van der Esch, Mirjam A.G.M. Pijnappels, Marco J.M. Hoozemans, \\ Marike van der Leeden, Leo D. Roorda, Joost Dekker, Willem F. Lems, and Jaap H. van Dieën
}

\begin{abstract}
Objective. We aimed to evaluate the associations between knee muscle strength (MS) and falls, controlling for knee joint proprioception, varus-valgus knee joint laxity, and knee pain, among patients with knee osteoarthritis (OA) reporting knee instability.

Methods. A sample of 301 subjects (203 women, 98 men, 35-82 yrs) with established knee OA and self-reported knee instability was studied. The occurrence of at least 1 fall in the previous 3 months was assessed by questionnaire. Maximum knee extension and flexion strength were measured isokinetically. Additionally, proprioception, varus-valgus laxity, and pain were assessed. Student t tests were used to assess differences between subgroups. The association of muscle strength and falls was calculated using univariate and multivariate logistic regression analysis.

Results. Over $10 \%$ of the subjects (31 out of 301) reported a fall in the previous 3 months. High knee extension muscle strength (crude OR $0.3,95 \%$ CI $0.1-0.8, \mathrm{p}=0.022$ ) and high knee flexion muscle strength (crude OR $0.2,95 \%$ CI $0.0-1.0, \mathrm{p}=0.048$ ) were associated with a lower risk of falls. Proprioception and laxity did not confound this relationship. After adjusting for pain, extensor strength had an adjusted OR of $0.5(95 \%$ CI $0.2-1.4, \mathrm{p}=0.212)$ for falls and flexor strength had an adjusted OR of $0.4(95 \%$ CI $0.1-2.3, \mathrm{p}=0.312)$.

Conclusion. High knee extension and flexion muscle strength decreased the risk of falls in patients with knee OA and self-reported knee instability. After considering the effect of pain, there was insufficient statistical power to detect an association between muscle strength and falls, which might be because of the low number of subjects who fell $(n=31)$. (First Release May 1 2015; J Rheumatol 2015;42:1218-23; doi:10.3899/jrheum.140517)
\end{abstract}

Keyword Indexing Terms:

ACCIDENTAL FALLS

MUSCLE STRENGTH
KNEE JOINT

PROPRIOCEPTION
OSTEOARTHRITIS

JOINT LAXITY
From the Amsterdam Rehabilitation Research Center/Reade; MOVE Research Institute Amsterdam, Faculty of Human Movement Sciences, VU University Amsterdam; Department of Rehabilitation Medicine, and Department of Psychiatry, and Department of Rheumatology, VU University Medical Center; Jan van Breemen Research Institute/Reade, Amsterdam, the Netherlands; King Abdulaziz University, Jeddah, Saudi Arabia.

A.H. de Zwart, MSc, Amsterdam Rehabilitation Research Center/Reade; M. Pijnappels, PhD, MOVE Research Institute Amsterdam, Faculty of Human Movement Sciences, VU University Amsterdam; M. van der Esch, PhD, Amsterdam Rehabilitation Research Center/Reade; M.J. Hoozemans, PhD, MOVE Research Institute Amsterdam, Faculty of Human Movement Sciences, VU University Amsterdam; M. van der Leeden, PhD, Amsterdam Rehabilitation Research Center/Reade, and Department of Rehabilitation Medicine, VU University Medical Center; L.D. Roorda, MD, PT, PhD, Amsterdam Rehabilitation Research Center/Reade; J. Dekker, PhD, Amsterdam Rehabilitation Research Center/Reade, and Department of Rehabilitation Medicine and Department of Psychiatry, VU University Medical Center; W.F. Lems, MD, PhD, Department of Rheumatology, VU University Medical Center, and Jan van Breemen Research

Institute/Reade; J.H. van Dieën, PhD, MOVE Research Institute Amsterdam, Faculty of Human Movement Sciences, VU University Amsterdam, and King Abdulaziz University.

Address correspondence to Dr. A.H. de Zwart, Amsterdam Rehabilitation Research Center/Reade, Amsterdam, the Netherlands.

E-mail:a.d.zwart@reade.nl

Accepted for publication March 9, 2015.
Falls are a leading cause of injuries, activity limitations, and death among older adults $1,2,3,4$. In patients with knee osteoarthritis (OA), the 1-year fall incidence has been reported to be about $30 \%$ higher than in healthy older adults of the same age $e^{5,6,7}$. Despite the elevated incidence of falls in patients with knee OA, the underlying mechanisms of falls in patients with knee OA are poorly understood.

Self-reported knee instability is the perception of slipping or giving way of the $\mathrm{knee}^{8}$. About $60-80 \%$ of the patients with knee OA report knee joint instability $9,10,11,12,13$. Muscle weakness is associated with knee joint instability 8,14 and is a known risk factor for falls in the general older population ${ }^{15}$ and arthritis population ${ }^{16}$. However, whether muscle weakness is (strongly) associated with falls in patients with knee OA is still unknown, yet relevant for their fall risk and treatment. It has been reported that patients with knee OA commonly generate lower maximum forces in knee flexors and extensors, the knee stabilizers ${ }^{17,18,19,20,21,22}$, than their healthy peers ${ }^{23,24}$. In knee OA, muscle weakness possibly arises because of neuromuscular inhibition by knee pain and muscle atrophy by avoidance of daily activities ${ }^{23,24}$. Muscle

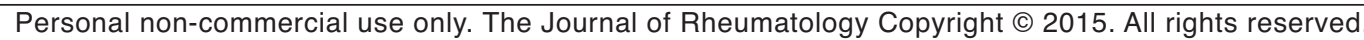


weakness might contribute to the high incidence of falls in patients with knee OA with self-reported knee instability ${ }^{8,14}$. Therefore, muscle weakness is hypothesized to be associated with falls in patients with knee OA and self-reported knee instability. Other factors may confound the relationship between muscle weakness and falling. Decreased proprioceptive accuracy, deficient or delayed detection of motion or position of the joint in knee OA may hamper fast and adequate responses to perturbations of knee motion ${ }^{25,26}$. High varus-valgus knee joint laxity might delay neuromuscular responses because relatively larger joint excursions are required to activate high threshold mechanoreceptors ${ }^{27}$. Finally, higher knee pain levels, a dominant symptom in knee $\mathrm{OA}^{2}$ and linked to knee instability ${ }^{8}$, might increase the risk of falls within this subgroup. Higher knee pain levels were reported in patients with lower-limb arthritis reporting falls than in patients with arthritis without falls ${ }^{16}$. This may be because of detrimental effects of pain on muscle strength ${ }^{28}$, but also on motor responses responsible for counteracting perturbations to avoid a fall ${ }^{25,26}$.

Knowledge of whether muscle strength is an important factor in the high numbers of falls reported in the knee OA population is essential for developing and prescribing adequate treatment. Therefore, the aim of our study was to evaluate the association between knee muscle strength and falls among patients with knee OA reporting knee instability, controlled for knee joint proprioception, varus-valgus knee joint laxity, and knee pain.

\section{MATERIALS AND METHODS}

Study population. A total of 301 patients with self-reported knee instability from the Amsterdam Osteoarthritis (AMS-OA) cohort, an open clinical population, were included in our study ${ }^{29}$. Knee instability was defined as the subjective perception of giving way of the knee. Subjects also had unilateral or bilateral knee OA according to the American College of Rheumatology (ACR). The AMS-OA is a cohort of patients with OA of the knee and/or hip according to the ACR criteria ${ }^{29,30}$ who have been referred to an outpatient rehabilitation center (Reade, Centre for Rehabilitation and Rheumatology, Amsterdam, the Netherlands). Patients were assessed by rheumatologists, radiologists, and rehabilitation physicians. Exclusion criteria were total knee replacement, hip OA, rheumatoid arthritis, or any other form of inflammatory arthritis (i.e., crystal arthropathy or septic arthritis). Demographic, clinical, radiographic, biomechanical, and psychosocial factors related to OA were assessed. All patients provided written informed consent according to the Declaration of Helsinki. The study was approved by the Slotervaart Hospital/Reade Institutional Review Board.

Outcome variable. Self-reported falls were assessed by a questionnaire at a dichotomous level according to Felson, $e a^{8} l^{8}$. Patients reported whether they had experienced at least 1 fall attributable to knee instability in the 3 months prior to their visit to the rehabilitation center. A fall was defined as an event in which a person unintentionally comes to rest on the ground or other lower levels ${ }^{31}$.

Independent variables. To measure muscle strength, maximum knee flexion (hamstring group) and extension strength (quadriceps group) were measured using an isokinetic dynamometer (EnKnee, Enraf-Nonius) for each leg in 3 test repetitions at $60 \% \mathrm{~s}^{32}$. We calculated mean (over both legs) muscle strength (in Nm) for knee flexion and extension, and normalized this to body mass (in $\mathrm{Nm} / \mathrm{kg}$ ). Excellent intrarater reliability (ICC 0.93 ) has been reported for the assessment of muscle strength using an isokinetic dynamometer ${ }^{33}$.
Proprioceptive accuracy of motion sense was assessed using a knee joint motion detection task. In a sitting position, both knees were moved to a starting position of $30^{\circ}$ flexion. From this position, computer-controlled constant angular motion of a single knee was started at a velocity of $0.3 \%$ in the extension direction ${ }^{32}$. The patient pushed either a left or right button when sensing knee joint motion of the left or right knee, respectively. Each knee was tested 3 times in a randomized order. Visual and auditory stimuli, mechanical vibrations, cutaneous tension, and pressure cues were minimized. The threshold for detection of knee joint motion was assessed by the difference of knee joint position, in degrees, between the actual onset of motion and the subject's detection of knee motion. We calculated the average value for the 3 measurements for each knee and the total average score including both legs. The average score of proprioception of the left and right knee was used in the statistical analysis. Intra- and interrater reliability for the assessment of knee proprioception using the test procedure described above (ICC 0.91) in patients with knee OA has been found to be excellent ${ }^{34}$.

Varus-valgus laxity of the knee was operationalized as the movement in the frontal plane after applying a load to the lower leg ${ }^{35,36}$. In a sitting position, the thigh and lower leg were fixed to the arms of the measurement device at 5 places. The thigh was fixed to the fixed arm of the device to prevent movement. With a fixed knee flexion of $20^{\circ}$, moments of $7.7 \mathrm{Nm}$ in varus and valgus directions were applied by means of a load of $1.12 \mathrm{~kg}$ attached to the free-moving arm by a cord at $0.68 \mathrm{~m}$ from the pivot. The patients were instructed to relax upper leg muscles during the performance of the test. The total amounts of movement in varus and valgus directions (in degrees) were summed. Three consecutive measurements were made, and right/left order was alternated between subjects. The mean of the 3 measurements for each knee and the mean score for both legs was calculated. The average score of knee joint laxity of the left and right knee was used in the statistical analysis. Intra- and interrater reliability (ICC) for this measurement in healthy adults is greater than 0.80 and 0.88 , respectively ${ }^{37}$.

Knee pain was assessed using a numerical rating scale (NRS) that ranged from 0 (no pain) to 10 (worst imaginable pain) ${ }^{38}$. The NRS has been shown to be a reliable and valid tool to measure pain levels, and is widely used in OA research ${ }^{39}$

Other measures. Age, sex, body mass index (BMI), and Kellgren-Lawrence score (KL score) were obtained. Age and sex were assessed by a questionnaire. Body mass and body height were measured to calculate BMI. The KL score is a radiological assessment of the severity of knee OA ranging from 0 (no radiographic features visible) to 4 (radiographic features: joint narrowing, osteophyte formation, cysts, sclerosis, and attrition are visible). A KL score of $\geq 2$ was considered radiographic knee $\mathrm{OA}^{40}$.

Statistical analysis. Descriptive statistics were used to characterize the total study population, those who fell, and those who did not fall. Normality checks (Kolmogorov-Smirnov tests, skewness, kurtosis, and histograms) were performed for all continuous variables. We performed Student $t$ tests and chi-square tests to test for differences between those who fell, and those who did not fall.

To address the aim of the study, logistic regressions analyses were performed to analyze the associations between muscle strength and falls. The dichotomous dependent variable was falls (i.e., absence vs the presence of a self-reported fall). The independent variable was knee muscle strength (either flexion or extension strength).

First, univariate logistic regression analyses were performed to assess the univariate association of muscle strength to fall incidents (crude models). Second, multivariate logistic regressions were performed to test the association between muscle strength and falls for confounding and interaction by including proprioception, laxity, and knee pain stepwise to the regression analyses. When proprioception, laxity, or knee pain changed the crude regression coefficient of muscle strength by more than $10 \%$, these variables were considered to be a confounder ${ }^{41}$. For the analysis with interaction terms, the independent variables of knee muscle strength, knee proprioception, knee joint laxity, and knee pain were centered on the mean because

Personal non-commercial use only. The Journal of Rheumatology Copyright @ 2015. All rights reserved. 
multicollinearity decreases when variables are centered ${ }^{42}$. Finally, a confounding role of general patient characteristics (age, sex, and KL score) was determined, based again on a $10 \%$ difference between the crude and adjusted regression coefficient.

Statistical significance was accepted for $\mathrm{p}$ values less than 0.05 and $95 \%$ CI for OR not crossing 1. All analyses were performed using SPSS software, version 18.0 (SPSS).

\section{RESULTS}

Differences in characteristics between those who fell and those who did not fall. Patient characteristics of the total study group and separately for those who fell and those who did not fall are presented in Table 1. Out of 301 patients, 31 patients with knee OA with knee instability (10\%) reported at least 1 fall incident in the previous 3 months. In those who reported falls, significantly lower extension strength (mean $0.81 \mathrm{Nm} / \mathrm{kg}$, SD 0.5) was measured than in those not reporting falls [mean $1.0 \mathrm{Nm} / \mathrm{kg}, \mathrm{SD} 0.5, \mathrm{t}(283)=2336, \mathrm{p}=$ 0.017 ], and significantly lower flexion strength (mean 0.53 $\mathrm{Nm} / \mathrm{kg}$, SD 0.3) compared with those not reporting falls [mean $0.68 \mathrm{Nm} / \mathrm{kg}$, SD 0.3, $\mathrm{t}(283)=2014, \mathrm{p}=0.041$ ]. Fallers reported higher pain levels (mean 6.13, SD 2.4) than non-fallers [mean 4.1, SD 2.7, $\mathrm{t}(297)=-4.076, \mathrm{p}<0.001]$. Those reporting falls showed no significant differences in proprioception (mean $3.1^{\circ}$, SD 2.0 ) and joint laxity (mean $8.0^{\circ}$, SD 3.4) compared with the others [mean $3.1^{\circ}$, SD 2.0, $\mathrm{t}(296)=-0.601, \mathrm{p}=0.830$, and mean $7.3^{\circ}, \mathrm{SD} 3.5, \mathrm{t}(272)=$ $-0.987, \mathrm{p}=0.214$, respectively].

Associations between muscle strength and falls. In Table 2, it is shown that knee extension (crude OR $0.3,95 \%$ CI $0.1-0.8, \mathrm{p}=0.022$ ) as well as knee flexion strength (crude OR $0.2,95 \%$ CI $0.0-1.0, \mathrm{p}=0.048$ ) were significantly associated with falls in patients with self-reported knee instability (i.e., higher muscle strength is significantly associated with the absence of self-reported incidental falls). Proprioceptive accuracy did not confound this association, and neither did knee joint laxity. Knee pain did affect the association between muscle strength and falls: extension strength (adjusted OR 0.5, 95\% CI 0.2-1.4, p=0.212) and flexion strength (adjusted OR 0.4, 95\% CI 0.1-2.3, $\mathrm{p}=0.312$ ). No significant interaction effects were found (data not shown). After including sex, age, and the KL score, stepwise, it was found that these variables did not confound the association between muscle strength and falls (data not shown).

\section{DISCUSSION}

In our present study, we focused on the associations between muscle strength and falls, and controlled for potential confounding factors (knee joint proprioception, knee joint varus-valgus laxity, and knee pain) in a group of established patients with knee OA reporting knee instability. It was shown that high knee flexor and extensor strength were associated with lower odds of falling. Proprioception and joint laxity did not confound this relationship. Knee pain might be associated with falls when entered in the model with muscle strength (OR 1.3, p $\leq 0.017)$ and might confound the association between muscle strength and falls. However, there was insufficient statistical power to detect the association between muscle strength and falls once considering the effect of pain. The results of our study indicate that upper leg muscle strength is an important factor with respect to incidental falls in patients with knee OA with self-reported knee instability.

In the general older population, upper leg muscle weakness is an important risk factor for falls ${ }^{4,15}$. Muscle weakness is a characteristic of patients with knee OA and is more severe in patients with knee OA compared with their

Table 1. Characteristics of study group.

\begin{tabular}{|c|c|c|c|c|c|}
\hline Characteristics & Total Group & $\begin{array}{c}\text { Those Reporting } \\
\text { Falls }\end{array}$ & $\begin{array}{c}\text { Those Not } \\
\text { Reporting Falls }\end{array}$ & $\mathrm{p}$ & Group Size* \\
\hline No. participants & 301 & 31 & 270 & - & - \\
\hline Female, $\%$ & 67.4 & 77.4 & 66.3 & 0.211 & $301(31)$ \\
\hline Age, yrs, (SD) & $61.5(8.3)$ & $61.4(9.7)$ & $61.5(8.1)$ & 0.835 & $301(31)$ \\
\hline $\mathrm{BMI}, \mathrm{kg} / \mathrm{m}^{2},(\mathrm{SD})$ & $30.6(6.1)$ & $32.7(7.5)$ & $30.3(5.9)$ & 0.088 & $301(31)$ \\
\hline \multicolumn{6}{|c|}{ Radiographic OA, KL score $\geq 2, \%$} \\
\hline Left & 57.3 & 74.1 & 55.4 & 0.064 & $267(27)$ \\
\hline Right & 58.6 & 75.0 & 56.7 & 0.063 & $268(28)$ \\
\hline $\begin{array}{l}\text { Extension strength, } \\
\mathrm{Nm} / \mathrm{kg} \text {, (SD) }\end{array}$ & $1.0(0.5)$ & $0.81(0.5)$ & $1.0(0.5)$ & 0.017 & $285(27)$ \\
\hline $\begin{array}{l}\text { Flexion strength, } \\
\mathrm{Nm} / \mathrm{kg} \text {, (SD) }\end{array}$ & $0.67(0.3)$ & $0.53(0.3)$ & $0.68(0.3)$ & 0.041 & $285(24)$ \\
\hline Proprioception, ${ }^{\circ},(\mathrm{SD})$ & $3.2(2.3)$ & $3.1(2.0)$ & $3.3(2.3)$ & 0.830 & $298(30)$ \\
\hline Laxity, ${ }^{\circ},(\mathrm{SD})$ & $7.3(3.5)$ & $8.0(3.4)$ & $7.2(3.5)$ & 0.214 & $274(22)$ \\
\hline $\begin{array}{l}\text { Knee pain severity, } \\
0-10,(\mathrm{SD})\end{array}$ & $4.3(2.7)$ & $6.13(2.4)$ & $4.1(2.7)$ & $<0.001$ & $299(31)$ \\
\hline
\end{tabular}

* Total no. participants for which data are available for each variable (no. those reporting falls for which data are available for each variable). Significant numbers are in bold face. BMI: body mass index; OA: osteoarthritis; KL: Kellgren and Lawrence. 
Table 2. Logistic regressions of falls* on biomechanical factors.

\begin{tabular}{|c|c|c|c|c|c|c|}
\hline \multirow[t]{2}{*}{ Models } & \multicolumn{3}{|c|}{ Extension } & \multicolumn{3}{|c|}{ Flexion } \\
\hline & OR & $95 \%$ CI & $\mathrm{p}$ & OR & $95 \% \mathrm{CI}$ & $\mathrm{p}$ \\
\hline 1. MS (crude) & 0.3 & $0.1-0.8$ & 0.022 & 0.2 & $0.0-1.0$ & 0.048 \\
\hline 2. MS (crude) & 0.4 & $0.1-0.9$ & 0.039 & 0.2 & $0.0-1.0$ & 0.052 \\
\hline MS + prop & $0.4^{* *}$ & $0.1-1.0$ & 0.046 & 0.2 & $0.0-1.1$ & 0.061 \\
\hline 3. MS (crude) & 0.5 & $0.2-1.3$ & 0.147 & 0.3 & $0.1-1.6$ & 0.158 \\
\hline $\mathrm{MS}+\mathrm{lax}$ & $0.5^{* *}$ & $0.2-1.4$ & 0.202 & $0.3^{* *}$ & $0.1-1.9$ & 0.207 \\
\hline 4. MS (crude) & 0.3 & $0.1-0.9$ & 0.024 & 0.2 & $0.0-1.0$ & 0.046 \\
\hline MS + pain & $0.5^{\ddagger}$ & $0.2-1.4$ & 0.212 & $0.4^{\ddagger}$ & $0.1-2.3$ & 0.312 \\
\hline
\end{tabular}

Model 1: MS (crude OR). Extension, $\mathrm{n}=285$. Flexion, $\mathrm{n}=285$. Model 2: MS crude and adjusted for proprioception. Extension, $\mathrm{n}=282$. Flexion, $\mathrm{n}=283$. Model 3: MS crude and adjusted for joint laxity. Extension, $\mathrm{n}=264$. Flexion, $\mathrm{n}=265$. Model 4: MS crude and adjusted for knee pain. Extension, $\mathrm{n}=283$. Flexion, $\mathrm{n}=283$. $*$ The dependent variable is coded $0=$ no fall and $1=$ fall. $* *$ No change in $\beta$ values $>10 \%$ found: changes seen

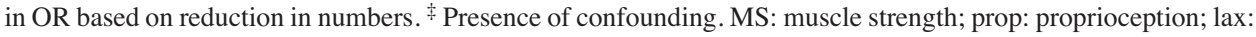
laxity.

healthy peers ${ }^{23,24}$. Sturnieks, et al $^{16}$ identified knee extension strength as an independent predictor of falls in older adults with lower extremity arthritis ${ }^{16}$. Our results are in line with this finding, although it should be noted that their results were based on older people with self-reported, nonspecific arthritis of the lower extremity without information on self-reported knee instability. In addition, our study showed that not only extension strength was associated with falls, but also low flexion strength. To our knowledge, no other studies on falls in patients with knee OA have reported both knee extension and flexion strength to be associated with falls. Lack of normalized muscle strength limits the ability to regain balance after external perturbations of gait ${ }^{43,44}$. Whether internal perturbations because of knee instability or giving way of the knee might result in a similar situation of disturbed balance, where muscle weakness limits the ability to regain balance, should be part of further research.

Proprioceptive accuracy in patients with knee OA has been shown to be impaired compared with healthy controls for both knee repositioning and motion sense $\mathrm{e}^{24,25,26,45,46}$. In our study, no significant difference in motion sense between those who fell and those who did not was found. Although motion sense is not equal to position sense, this result is in line with the findings of Sturnieks, et $a l^{16}$. Our current study suggests that a decrease in proprioceptive accuracy is of less importance than low knee flexor and extensor strength. However, proprioception has been suggested as an important determinant of function in this patient population $5,6,7,32$. Therefore, future studies on the role of decreased proprioceptive accuracy on falls are necessary.

Varus-valgus joint laxity was not different between groups, and it did not affect the association between muscle strength and falls. Reeves, et al have suggested that joint laxity refers to static stability and might therefore not be predictive for falls occurring during dynamic activities ${ }^{47}$. This suggests that falls would be more related to dynamic stability and less to laxity of the knee joint. For example, dynamic stability during gait can be expressed in terms of the Lyapunov exponent ${ }^{48}$. The suitability of assessing dynamic gait stability measures with respect to falls in patients with knee OA needs to be further explored.

Knee pain was associated with falls and with extension strength $(\mathrm{r}=-0.339, \mathrm{p}<0.01)$ and flexion strength $(\mathrm{r}=-0.377$, $\mathrm{p}<0.01$ ), and affected the association between knee muscle strength and falls. However, because of the small number of fallers $(n=31)$, there was insufficient statistical power to detect an association between muscle strength and falls once considering the strong influence of knee pain on this association. Previous research showed that knee pain in women with knee OA is a risk factor for falls ${ }^{49}$. However, the mechanism by which pain contributes to falls in patients with knee OA is unknown. It can be speculated that the avoidance of pain, by decreasing force on the affected knee, may alter gait and lead toward a pattern more prone to falls ${ }^{50}$. Moreover, the presence of pain might cause muscle weakness through pain-related muscle inhibition ${ }^{24}$ that in turn may limit the ability to regain balance after a perturbation ${ }^{43,44}$. Although it is unclear in which manner knee muscle strength and pain increase the risk of falls in patients with knee OA and self-reported knee instability, both are important underlying factors in falls.

Our study has several limitations. First, the study population presented consisted of only patients with knee OA with self-reported knee instability. No information on fall incidents was available for patients with knee OA without self-reported knee instability. Therefore, our study focused on fall incidents in the subgroup of patients with knee OA reporting knee instability. This subgroup, however, concerns a large part of the total knee OA population, ranging from 60-80\% ${ }^{9,10,11,12,13}$. Second, falls were reported, retrospectively, over the last 3 months only, and whether these reported falls actually occurred and whether all falls were reported is unknown. Third, no information was available on the use of pain medication that is a known risk factor on falls ${ }^{15}$. Fourth,

Personal non-commercial use only. The Journal of Rheumatology Copyright @ 2015 . All rights reserved. 
the study design was cross-sectional and hence causality cannot be inferred. Finally, not all patients' data were available for all measurements of muscle strength, proprioception, or laxity (Table 1, last column) because in various cases, it was impossible to perform all measurements.

High knee extension and flexion muscle strength are associated with lower odds of fall events in patients with knee $\mathrm{OA}$ and self-reported knee instability. However, there was insufficient statistical power to detect the association between muscle strength and falls once considering the strong influence of knee pain on this association. Knee pain should be considered as an independent variable in the risk of falls in future research.

\section{REFERENCES}

1. Ambrose AF, Paul G, Hausdorff J. Risk factors for falls among older adults: a review of the literature. Maturitas 2013;75:51-61.

2. Hoops ML, Rosenblatt NJ, Hurt CP, Crenshaw J, Grabiner MD. Does lower extremity osteoarthritis exacerbate risk factors for falls in older adults? Womens Health 2012;8:685-96.

3. Kenny RA, Romero-Ortuno R, Cogan L. Falls. Medicine 2009;37:84-7.

4. Rubenstein LZ, Josephson KR. The epidemiology of falls and syncope. Clin Geriatr Med 2002;18:141-58.

5. Brand C, Aw J, Lowe A, Morton C. Prevalence, outcome and risk for falling in 155 ambulatory patients with rheumatic disease. APLAR J Rheumatol 2005;8:99-105.

6. Kelsey JL, Berry SD, Procter-Gray E, Quach L, Nguyen US, Li W, et al. Indoor and outdoor falls in older adults are different: the maintenance of balance, independent living, intellect, and Zest in the Elderly of Boston Study. J Am Geriatr Soc 2010;58:2135-41.

7. Williams SB, Brand CA, Hill KD, Hunt SB, Moran H. Feasibility and outcomes of a home-based exercise program on improving balance and gait stability in women with lower-limb osteoarthritis or rheumatoid arthritis: a pilot study. Arch Phys Med Rehabil 2010;91:106-14.

8. Felson DT, Niu J, McClennan C, Sack B, Aliabadi P, Hunter DJ, et al. Knee buckling: prevalence, risk factors, and associated limitations in function. Ann Intern Med 2007;147:534-40.

9. Fitzgerald GK, Piva SR, Irrgang JJ. Reports of joint instability in knee osteoarthritis: its prevalence and relationship to physical function. Arthritis Rheum 2004;51:941-6.

10. Lewek MD, Ramsey DK, Snyder-Mackler L, Rudolph KS. Knee stabilization in patients with medial compartment knee osteoarthritis. Arthritis Rheum 2005;52:2845-53.

11. Lewek MD, Rudolph KS, Snyder-Mackler L. Control of frontal plane knee laxity during gait in patients with medial compartment knee osteoarthritis. Osteoarthritis Cartilage 2004;12:745-51.

12. Ramsey DK, Snyder-Mackler L, Lewek M, Newcomb W, Rudolph KS. Effect of anatomic realignment on muscle function during gait in patients with medial compartment knee osteoarthritis. Arthritis Rheum 2007;57:389-97.

13. Schmitt LC, Fitzgerald GK, Reisman AS, Rudolph KS. Instability, laxity, and physical function in patients with medial knee osteoarthritis. Phys Ther 2008;88:1506-16.

14. Knoop J, van der Leeden M, van der Esch M, Thorstensson CA, Gerritsen M, Voorneman RE, et al. Association of lower muscle strength with self-reported knee instability in osteoarthritis of the knee: results from the Amsterdam Osteoarthritis Cohort. Arthritis Care Res 2012;64:38-45.

15. Lord SR, Ward JA, Williams P, Anstey KJ. Physiological factors associated with falls in older community-dwelling women. J Am
Geriatr Soc 1994;42:1110-7

16. Sturnieks DL, Tiedemann A, Chapman K, Munro B, Murray SM, Lord SR. Physiological risk factors for falls in older people with lower limb arthritis. J Rheumatol 2004;31:2272-9.

17. Bennell KL, Hunt MA, Wrigley TV, Lim BW, Hinman RS. Role of muscle in the genesis and management of knee osteoarthritis. Rheum Dis Clin North Am 2008;34:731-54.

18. Hubley-Kozey CL, Deluzio KJ, Landry SC, McNutt JS, Stanish WD. Neuromuscular alterations during walking in persons with moderate knee osteoarthritis. J Electromyogr Kinesiol 2006; 16:365-78.

19. Jackson BD, Wluka AE, Teichtahl AJ, Morris ME, Cicuttini FM. Reviewing knee osteoarthritis - a biomechanical perspective. J Sci Med Sport 2004;7:347-57

20. Rutherford DJ, Hubley-Kozey CL, Stanish WD, Dunbar MJ. Neuromuscular alterations exist with knee osteoarthritis presence and severity despite walking velocity similarities. Clin Biomech 2011;26:377-83.

21. Schipplein OD, Andriacchi TP. Interaction between active and passive knee stabilizers during level walking. J Orthop Res 1991;9:113-9.

22. Segal NA, Glass NA, Felson DT, Hurley M, Yang M, Nevitt M, et al. Effect of quadriceps strength and proprioception on risk for knee osteoarthritis. Med Sci Sports Exerc 2010;42:2081-8.

23. Fisher NM, Pendergast DR. Reduced muscle function in patients with osteoarthritis. Scand J Rehabil Med 1997;29:213-21.

24. Hassan BS, Mockett S, Doherty M. Static postural sway, proprioception, and maximal voluntary quadriceps contraction in patients with knee osteoarthritis and normal control subjects. Ann Rheum Dis 2001;60:612-8.

25. Barrett DS, Cobb AG, Bentley G. Joint proprioception in normal, osteoarthritic and replaced knees. J Bone Joint Surg Br 1991; 73:53-6.

26. Marks R, Quinney HA, Wessel J. Proprioceptive sensibility in women with normal and osteoarthritic knee joints. Clin Rheumatol 1993;12:170-5.

27. Fernandes N, Allison GT, Hopper D. Peroneal latency in normal and injured ankles at varying angles of perturbation. Clin Orthop Relat Res 2000;375:193-201.

28. Hassan BS, Doherty SA, Mockett S, Doherty M. Effect of pain reduction on postural sway, proprioception, and quadriceps strength in subjects with knee osteoarthritis. Ann Rheum Dis 2002;61:422-8.

29. Altman R, Asch E, Bloch D, Bole G, Borenstein D, Brandt K, et al. Development of criteria for the classification and reporting of osteoarthritis. Classification of osteoarthritis of the knee. Diagnostic and therapeutic criteria committee of the American Rheumatism Association. Arthritis Rheum 1986;29:1039-49.

30. Altman R, Alarcon G, Appelrouth D, Bloch D, Borenstein D, Brand $\mathrm{K}$, et al. The American College of Rheumatology criteria for the classification and reporting of osteoarthritis of the hip. Arthritis Rheum 1991;34:505-14.

31. Gibson MJ, Andres RO, Kennedy TE, Coppard LC. The prevention of falls in later life. A report of the Kellogg International Work Group on the Prevention of Falls by the Elderly. Dan Med Bull 1987;34 Suppl 4:1-24.

32. van der Esch M, Steultjens M, Harlaar J, Knol D, Lems W, Dekker J. Joint proprioception, muscle strength, and functional ability in patients with osteoarthritis of the knee. Arthritis Rheum 2007;57:787-93.

33. Kean CO, Birmingham TB, Garland SJ, Bryant DM, Giffin JR. Minimal detectable change in quadriceps strength and voluntary muscle activation in patients with knee osteoarthritis. Arch Phys Med Rehabil 2010;91:1447-51.

34. Hurkmans EJ, van der Esch M, Ostelo RW, Knol D, Dekker J, Steultjens MP. Reproducibility of the measurement of knee joint 
proprioception in patients with osteoarthritis of the knee. Arthritis Rheum 2007;57:1398-403.

35. van der Esch M, Steultjens M, Knol DL, Dinant H, Dekker J. Joint laxity and the relationship between muscle strength and functional ability in patients with osteoarthritis of the knee. Arthritis Rheum 2006;55:953-9.

36. van der Esch M, Steultjens M, Wieringa H, Dinant H, Dekker J. Structural joint changes, malalignment, and laxity in osteoarthritis of the knee. Scand J Rheumatol 2005;34:298-301.

37. van der Esch M, Steultjens M, Ostelo RW, Harlaar J, Dekker J. Reproducibility of instrumented knee joint laxity measurement in healthy subjects. Rheumatology 2006;45:595-9.

38. Jensen MP, Karoly P. Self-report scales and procedures for assessing pain in adults. In: Turk DC, Melzack R, eds. Handbook of pain assessment, 2 edition. New York: The Guilford Press; 2001:15-34.

39. Hawker GA, Mian S, Kendzerska T, French M. Measures of adult pain: Visual Analog Scale for Pain (VAS Pain), Numeric Rating Scale for Pain (NRS Pain), McGill Pain Questionnaire (MPQ), Short-Form McGill Pain Questionnaire (SF-MPQ), Chronic Pain Grade Scale (CPGS), Short Form-36 Bodily Pain Scale (SF-36 BPS), and Measure of Intermittent and Constant Osteoarthritis Pain (ICOAP). Arthritis Care Res 2011;63 Suppl 11:240-52.

40. Kellgren JH, Lawrence JS. Radiological assessment of osteo-arthrosis. Ann Rheum Dis 1957;16:494-502.

41. Kleinbaum D, Kupper L, Muller K, Nizam A. Confounding and interaction in regression. In: Kleinbaum DG, Kupper LL, Nizam A, Muller KE, eds. Applied regression analysis and other multivariable methods. Pacific Grove: Duxbury Press; 1998:186-211.
42. Aiken LS, West SG. Multiple regression: testing and interpreting interactions. Newbury Park: Sage; 1991.

43. Pijnappels M, Bobbert MF, van Dieën JH. Push-off reactions in recovery after tripping discriminate young subjects, older non-fallers and older fallers. Gait Posture 2005;21:388-94.

44. Pijnappels M, van der Burg PJ, Reeves ND, van Dieën JH. Identification of elderly fallers by muscle strength measures. Eur J Appl Physiol 2008;102:585-92.

45. Knoop J, Steultjens MP, van der Leeden M, van der Esch M, Thorstensson CA, Roorda LD, et al. Proprioception in knee osteoarthritis: a narrative review. Osteoarthritis Cartilage 2011;19:381-8.

46. Sharma L, Pai YC, Holtkamp K, Rymer WZ. Is knee joint proprioception worse in the arthritic knee versus the unaffected knee in unilateral knee osteoarthritis? Arthritis Rheum 1997;40:1518-25.

47. Reeves ND, Narendra KS, Cholewicki J. Spine stability: the six blind men and the elephant. Clinic Biomech 2007;22:266-74.

48. Bruijn SM, Meijer OG, Beek PJ, van Dieën JH. Assessing the stability of human locomotion: a review of current measures. J R Soc Interface 2013;10:20120999.

49. Muraki S, Akune T, Ishimoto Y, Nagata K, Yoshida M, Tanaka S, et al. Risk factors for falls in a longitudinal population-based cohort study of Japanese men and women: the ROAD Study. Bone 2013;52:516-23.

50. Fallah Yakhdani H. Gait characteristics in knee osteoarthritis patients before and after knee replacement [dissertation]. Amsterdam: VU University; 2011:102. 